\title{
A NEW APPROACH TO THE SLIDING MODE CONTROL DESIGN: ANTI-LOCK BRAKING SYSTEM AS A CASE STUDY
}

\author{
Staniša Lj. Perić ${ }^{*}$ - Dragan S. Antić ${ }^{*}$ - Vlastimir D. Nikolić ${ }^{* *}$ \\ Darko B. Mitić $^{*}$ - Marko T. Milojković ${ }^{*}$ - Saša S. Nikolić ${ }^{*}$
}

\begin{abstract}
In this paper we introduce a new approach to the sliding mode control design based on orthogonal models. First, we discuss the sliding mode control based on a model given in controllable canonical form. Then, we design almost orthogonal filters based on almost orthogonal polynomials of Müntz-Legendre type. The advantage of the almost orthogonal filters is that they can be used for the modelling and analysis of systems with nonlinearities and imperfections. Herein, we use a designed filter to obtain several linearized models of an unknown system in different working areas. For each of these linearized models, corresponding sliding mode controller is designed and the switching between controls laws depends only on input signal. The experimental results and comparative analysis with relay control, already installed in laboratory equipment, verify the efficiency and excellent performance of such a control in the case of anti-lock braking system.
\end{abstract}

K e y w o r d s: sliding mode control; orthogonal model; controllable canonical form; anti-lock braking system

\section{INTRODUCTION}

Sliding mode control $[1,2]$ is a popular approach to the robust control of systems with parameters uncertainties as well as highly nonlinear systems. The principal goal of the sliding mode control technique is to force a system state to a certain prescribed manifold, known as the sliding surface. Once the manifold is reached, the system is forced to remain on it thereafter. When in the sliding mode, the system is equivalent to an unforced system of lower order, which is insensitive to both parametric uncertainty and unknown disturbances that satisfy the matching condition. The main drawback of the sliding mode control (SMC) is the requirement of a discontinuous control law across the sliding surface. In practical systems this leads to a phenomenon called chattering. Chattering involves high-frequency control switching and may lead to excitation of unmodelled high-frequency system dynamics. Chattering also cause high heat losses in electronic systems and undue wear in mechanical systems.

Most of the SMC techniques proposed in the literature have been developed mainly based on the statespace model with the assumption that all state variables are measurable or on the input-output model for a linear system. In paper [3], the robust controller based on internal process model and sliding mode control concepts is proposed. A model-based sliding mode controller for extensible continuum robots is developed in [4]. The similar approach, but for the HDA-plant, is presented in [5]. One interesting example of model-based control is described in [6], where the novel sliding mode controller is based on Takagi-Sugeno fuzzy model.
On the other hand, in some control problems we are allowed to access only the inputs and the outputs of the nonlinear plant. This is where the multiple model-based control frameworks can be very attractive for nonlinear control problems since it is capable of not only utilizing this robust control technique for nonlinear systems but also applying it for unknown systems. The concept of multiple models with switching has received considerable attention in recent years since it simplifies both the modelling and the controller design [7]. If a system which needs to be modelled is complicated, there is no guarantee that any given global representation will approximate system equally well across all space. In this case, the dependence on representation can be reduced using local approximation where the domain of system is divided into local regions and a separate model is used for each region [8]. In paper [9], a multiple discrete quasi sliding mode control scheme is proposed for a general class of nonlinear discrete time systems, where the self-organizing map is employed to divide the state space into local regions.

The model of certain working area of system can be also described by $n$-th order transfer function using orthogonal filters. New methods for obtaining orthogonal functions and their applications in the field of engineering have been the subject of intensive research of authors of this paper. In $[10,11]$ we presented a new method for designing orthogonal rational functions using specific transformations in complex domain and derived a necessary mathematical background. We also presented a new method for obtaining models of continuous dynamical systems based on these orthogonal functions [12]. Practical realization of derived orthogonal filters is very simple due to factorized form of orthogonal functions and they

\footnotetext{
* University of Niš, Faculty of Electronic Engineering, Department of Control Systems, Aleksandra Medvedeva 14, 18000 Niš, Republic of Serbia, stanisa.peric@elfak.ni.ac.rs, ${ }^{* *}$ University of Niš, Faculty of Mechanical Engineering, Department of Mechatronics and Automatic Control, Aleksandra Medvedeva 14, 18000 Niš, Republic of Serbia.
} 
are very fast, robust and precise. They are also very convenient for application of gradient methods in optimization and adaptation problems because of their feature to speed up existing (classical) control algorithms.

In this paper we go one step forward and use developed Müntz-Legendre almost orthogonal filter to improve existing sliding mode control technique by building linearized local orthogonal models of the plant to be controlled. It is well known that effectiveness of control method is closely related to model accuracy. On the other hand, the orthogonal models, characterized by corresponding transfer function, cannot be directly used in control algorithm. It was pointed out that due to the differentiable features of the object, the orthogonal models have to be transformed into modified controllable canonical form and then used as plant in the design of sliding mode control.

To verify the effectiveness and applicability of the proposed approach, we apply it to anti-lock braking system, characterized by strong nonlinear and uncertain characteristics. ABS is an electronic system which monitors and controls wheel slip during vehicle braking, helping secure stopping of the vehicle. The main objective of designed controller is to provide the best adhesion of a wheel to a surface while keeping the wheel slip ratio at desired level. We have performed experiment with relay controller and results are compared with those obtained by proposed sliding mode control using the almost orthogonal filter. The experimental results show that proposed control algorithm gives better system performances in terms of smaller stopping time and lower tracking error. It is also shown that higher number of models provides better control features, of course with the price of higher complexity and cost of designed controller.

\section{SLIDING MODE CONTROL OF A LINEAR SYSTEM WITH FINITE STABLE ZEROS}

Let consider $n$-th order plant with $m$ finite stable zeros described by the following transfer function

$$
W(s)=\frac{P(s)}{Q(s)}=\frac{b_{m} s^{m}+b_{m-1} s^{m-1}+\cdots+b_{0}}{s^{n}+a_{n-1} s^{n-1}+\cdots+a_{0}},
$$

where $\operatorname{deg} P(s)=m, \operatorname{deg} Q(s)=n$, and $m<n$.

The problem of implementing sliding modes for such objects has been discussed in several papers [13-15]. It was pointed out there that due to the differentiable features of the object, the sliding mode could not be implemented by the control suffering from break, which is characteristic of variable structure systems. To overcome this problem, the control break signal can be passed through the first-order low-pass filter cascade [16]. The second approach is to divide the starting system, given by the model in the controllable canonical form

$$
\begin{aligned}
& \dot{x}=A x+b u, x \in R^{n}, u \in R^{m}, \\
& y=h x,
\end{aligned}
$$

into two subspaces [17]. The first $m$-th order subspace is autonomous with stable eigenvalues, while the second one depends on control signal and it is of $(n-m)$-th order. In that way, sliding mode control can be developed in this subspace providing in that manner the stability over the whole system. Further, the theoretical background of this method is given briefly [17].

Let consider the system (2) and let assume that some coordinate

$$
y_{1}=h_{0} x, h_{0}=\left(h_{01}, h_{02}, \ldots, h_{0 n}\right),
$$

is controlled variable, while it is assumed that pair $(A, b)$ is controllable and $\left(h_{0}, A\right)$ is observable. To reduce $(2)$ to the modified controllable canonical form, we can start with desired model representation given by

$$
\begin{aligned}
& y_{1}^{(i)}=h_{0} A^{i} x, i=(0,1, \ldots, l-1), \\
& y_{1}^{(l)}=h_{0} A^{l} x+h_{0} A^{l-1} b u .
\end{aligned}
$$

Now, let introduce notations

$$
\begin{aligned}
& \dot{y}_{i}=y_{i+1}, i=(1,2, \ldots, l-1), \\
& \dot{y}_{l}=h_{0} A^{l} x+h_{0} A^{l-1} b u .
\end{aligned}
$$

The system consisting of the first $l$ equations in (4) can be solved with respect to $l$ components of the vector $x$. Enumerate $x$ so as to make these $l$ components constitute a vector

$$
\left(x^{l}\right)^{\top}=\left(x_{n-l+1}, \ldots, x_{n}\right),
$$

then

$$
x^{l}=R x^{n-l}+R_{y} y^{l},
$$

where $x^{n-l}=\left(x_{1}, \ldots, x_{n-l}\right), y^{l}=\left(y_{1}, \ldots, y_{l}\right)^{\top}$, and the constant matrices $R$ and $R_{y}$ are defined as the result of solving the system of $l$ equations of (4) with respect to $x^{l}$. By substituting the system (5) for last $l$ equations in (2) and linear functions (7) for $x^{l}$ in all the equations, we finally obtain equations describing the system behaviour in the state space $x^{n-l}, y^{l}$

$$
\begin{aligned}
\dot{x}^{n-l} & =A_{n-l} x^{n-l}+D y^{l}+b^{n-l} u, \\
\dot{y}_{i} & =y_{i+1}, i=1, \ldots, l-1, \\
\dot{y}_{l} & =r^{n-l} x^{n-l}+d^{l} y^{l}+h_{0} A^{l-1} b u,
\end{aligned}
$$

where $A_{n-l}, D, b^{n-l}, r^{n-l}$ and $d^{l}$ are constant matrices, vector and rows of corresponding dimensionality. The last equation provides the form suitable for the sliding mode controller design.

The most common sliding mode control structure is chosen as

$$
u(t)=u_{\mathrm{fed}}(t)+u_{\mathrm{dis}}(t),
$$




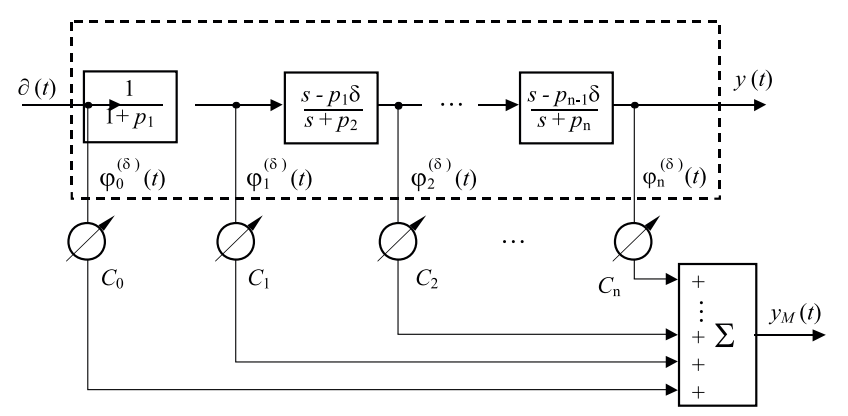

Fig. 1. Adjustable Müntz-Legendre almost orthogonal model

where $u_{\text {fed }}(t)$ is a stable feedback control law, usually the nominal equivalent control [18], and $u_{\text {dis }}(t)$ is a discontinuous or switching component. The main goal of equivalent control method is to keep the system trajectory on sliding surface, while second term in (9) ensures a system state to hit a sliding surface from any initial point.

Having in mind the fact that sliding motion is now induced in an $l$-dimensional subspace on the plane

$$
s=c y^{l}=0
$$

where $c=\left(c_{1}, \ldots, c_{l-1}, 1\right)$. We can obtain the equivalent control from the equation

$$
\dot{s}=\sum_{i=1}^{l-1} c_{i} y_{i+1}+r^{n-l} x^{n-l}+d^{l} y^{l}+h_{0} A^{l-1} b u=0
$$

$$
\begin{aligned}
& u_{e q}(t)=u_{\mathrm{fed}}(t)= \\
& -\left(h_{0} A^{l-1} b\right)^{-1}\left(\sum_{i=1}^{l-1} c_{i} y_{i+1}+r^{n-l} x^{n-l}+d^{l} y^{l}\right) .
\end{aligned}
$$

The discontinuous part in control law (9) usually depends on the control problem. In the case of regulator type controller, it can be chosen as scaled relay structure

$$
u_{\mathrm{dis}}(t)=-\rho \operatorname{sgn}(s),
$$

where $\rho$ is parameter chosen to satisfy the reaching and existence conditions of sliding mode.

In order to improve the existing sliding mode control, we can use orthogonal models, obtained using the orthogonal filters, described in the following section. In such a way, we can linearize any given system in its working areas with high percentage of accuracy, which is of great importance for controller design. Next step is to develop sliding mode controller for each working area.

\section{ORTHOGONAL MODELS}

In our previous work, we have developed orthogonal filters [20], almost orthogonal filters [19], and improved almost orthogonal filters [11]. Moreover, we have proved that they are very useful tool for modelling [12], control of dynamical systems [10], and approximation of signals [11]. Also, these filters can be used for sensitivity analysis of continuous systems [21].

In these papers, almost orthogonal filters contain a measure of imperfection labelled as $\varepsilon$ (constant close to zero), which describes cumulative impacts of all imperfect elements [12]. These coefficients can be determined using several experiments. In [11] we considered new filters, which represent the further improvement of filters designed in [12], in the sense of simplicity, higher accuracy, lesser approximation time, and even a possibility to approximate signals generated by systems with built-in imperfections. These filters can be used for generating of sequences of functions, approximations, modelling, control and analysis of imperfect systems.

In this paper, we use improved adjustable almost orthogonal filter of Müntz-Legendre type [11] shown in Fig. 1 for the purpose of the modelling of dynamical system, as a first step in designing the adequate control.

As already proven in [11], this filter generates orthogonal signals $\varphi_{i}^{(\delta)}(t)$ suitable for various applications in analysis and synthesis of technical systems. First, we define almost orthogonal Müntz-Legendre polynomials

$$
P_{n}^{(\delta)}(x)=\sum_{i=0}^{n} A_{n, i}^{\delta} x^{i}
$$

where $\delta$ is a constant little above one: $\delta=1+\varepsilon \approx 1$. Parameter $\delta$ is uncertain quantity, which describes imperfection of the system and it is introduced to facilitate the practical realization of filter. Variations of $\delta$ contain cumulative impacts of all imperfect elements, model uncertainties, and measurement noise on the system output. Range of variations can be determined by conducting several experiments. Hence, it is expected that responses obtained from different experiments are mutually different. The responses are in certain boundaries, which depend on parameter $\delta$, ie, on the real system components quality, or the noise level present in signal.

After applying the substitution $x=e^{-t}$ to (14) and Laplace transform, we obtain transfer function suitable for designing almost orthogonal filters

$$
\begin{aligned}
W_{n}^{(\delta)}(s)=\frac{\prod_{i=1}^{n-1}\left(s-p_{i} \delta\right)}{\prod_{i=1}^{n}\left(s+p_{i}\right)}= \\
\frac{\left(s-p_{1} \delta\right)\left(s-p_{2} \delta\right) \ldots\left(s-p_{n-1} \delta\right)}{\left(s+p_{1}\right)\left(s+p_{2}\right) \ldots\left(s+p_{n}\right)}
\end{aligned}
$$

The transfer function (15) is also very convenient for practical realization $[10,11]$. The complete mathematical background is given in [11]. The following approximation is used to obtain the model of an arbitrary dynamical system

$$
y_{M}(t) \approx \sum_{i=0}^{n} c_{i} \varphi_{i}^{(\delta)}(t)
$$


Table 1. Parameters of the linearized system for different working areas

\begin{tabular}{cccccccr}
\hline $\begin{array}{c}\text { model } \\
\text { number }\end{array}$ & $\begin{array}{c}\text { braking } \\
\text { force } \\
\text { range }\end{array}$ & $\begin{array}{c}\text { applied } \\
\text { value }\end{array}$ & $b_{1}$ & $b_{0}$ & $a_{1}$ & $a_{0}$ \\
\hline 1 & $0.20-0.21$ & 0.205 & 0.487 & 38.546 & 64.631 & 935.329 \\
2 & $0.21-0.22$ & 0.215 & 0.138 & 73.974 & 92.113 & 1409.402 \\
3 & $0.22-0.23$ & 0.225 & 0.704 & 17.922 & 31.129 & 242.056 \\
4 & $0.23-0.24$ & 0.235 & 0.859 & 21.865 & 40.301 & 180.211 \\
5 & $0.24-0.25$ & 0.245 & 0.997 & 11.773 & 19.013 & 77.423 \\
6 & $0.25-0.26$ & 0.255 & 0.612 & 32.414 & 52.532 & 192.221 \\
7 & $0.26-0.27$ & 0.265 & 0.387 & 44.781 & 38.631 & 247.572 \\
8 & $0.27-0.28$ & 0.275 & 0.293 & 63.215 & 44.615 & 288.311 \\
9 & $0.28-0.29$ & 0.285 & 0.385 & 51.552 & 37.399 & 177.881 \\
10 & $0.29-0.30$ & 0.295 & 0.611 & 89.925 & 68.212 & 268.331 \\
11 & $0.30-0.31$ & 0.305 & 0.544 & 93.616 & 66.518 & 273.144 \\
12 & $0.31-0.32$ & 0.315 & 0.277 & 48.355 & 27.111 & 132.473 \\
13 & $0.32-0.33$ & 0.325 & 0.305 & 52.719 & 28.841 & 142.818 \\
14 & $0.33-0.34$ & 0.335 & 0.382 & 59.616 & 30.217 & 153.151 \\
15 & $0.34-0.35$ & 0.345 & 0.518 & 74.126 & 37.652 & 187.116 \\
16 & $0.35-0.36$ & 0.355 & 0.596 & 84.853 & 44.282 & 198.173 \\
17 & $0.36-0.37$ & 0.365 & 0.635 & 95.751 & 52.113 & 210.220 \\
18 & $0.37-0.38$ & 0.375 & 0.655 & 103.884 & 53.249 & 219.690 \\
19 & $0.38-0.39$ & 0.385 & 0.518 & 99.414 & 52.122 & 195.301 \\
20 & $0.39-0.40$ & 0.395 & 0.855 & 35.227 & 18.744 & 66.366 \\
\hline
\end{tabular}

where $\varphi_{i}^{(\delta)}(t)$ represent Müntz-Legendre type almost orthogonal functions generated by almost orthogonal filter shown in Fig. 1.

During the modelling of concrete unknown system, parameters ci should be adjusted in such a way that the model in Fig. 1 corresponds to the unknown system as exactly as possible. The process of modelling begins with applying the same input signal to both the unknown system and the adjustable model in Fig. 1. Next, the difference of system and model outputs is formed as well as mean square error

$$
J=\frac{1}{T} \int_{0}^{T}\left(y_{S}-y_{M}\right)^{2} \mathrm{~d} t
$$

where $y_{S}$ and $y_{M}$ are system and model outputs, respectively. Parameters $c_{i}$ are being adjusted until the minimization of the function (17) is achieved, ie, as long as necessary to obtain the best model of unknown system in the sense of mean square error. The complete process of modelling is given in $[11,12]$.

\section{ANTI-LOCK BRAKING SYSTEM}

Theoretical algorithm developed in this paper is verified on a case study of an anti-lock braking system (ABS). $\mathrm{ABS}$ is an electronic device, situated inside the vehicle control panel, which is activated when the possibility of blocking wheel is met. The main idea is that, during suddenly braking, the wheels do not block completely. The coefficient which characterizes the adhesion between the wheels and the road surface is known as road adhesion coefficient $\mu$. It is defined as the proportion between the friction force and the normal load of the vehicle. This coefficient is in nonlinear dependence on the wheel slip $\lambda$, defined as the relative speed difference between the wheel and vehicle. Most of the controllers are designed to regulate wheel slip on the pre-set level, in desired range, so that the road adhesion coefficient has its maximal value for that level of wheel slip.

The ABS experimental setup [22] consists of two wheels which are permanently in rolling contact. While the upper wheel is equipped with a tire, representing the vehicle wheel, the lower one, representing the relative road motion, has smooth surface. The upper wheel is also equipped with the disk brake system connected via hydraulic coupling to the brake lever which by the tight side and tightening pulley is driven by the small dc motor. The lower wheel is coupled to the big flat dc motor whose task is to accelerate the wheel. During the braking phase its power supply is switched off.

The steel cord causes strong nonlinearity and limitation of control input signal on $50 \%$ of its maximum nominal value. The main system nonlinearity is reflected in complex braking dynamic characteristics. Besides that, the system parameters vary, and many external disturbances cannot be predicted in advance. That is why sliding mode control (SMC) method seems to be the right choice in the control of ABS.

\section{CASE STUDY}

Application of orthogonal functions in ABS control is based on linearization of the system in the working areas. These simplified models don't represent full complexity of the real system but they determine system dynamics in specific conditions adequately enough. Paper [23] demonstrates that ABS simplified linearized model can be represented with the following transfer function (input - applied braking force, output - wheel slip)

$$
W(s)=\frac{b_{1} s+b_{0}}{s^{2}+a_{1} s+a_{0}}
$$

where $b_{1}$ and $b_{0}$ depend on parameter $\delta$.

The idea proposed in this paper is to record responses of the system (values of wheel slip $\lambda$ ) in different working areas, for various levels of applied control (braking force) evenly selected from the domain of possible values [24]. Based on these responses we can linearize system in the given areas using orthogonal polynomials, as already described in Section 3. For this case, we use improved adjustable almost orthogonal filter of Müntz-Legendre type shown in Fig. 1 with two sections, which results in the desired form of transfer function (18). The obtained results after modelling are shown in Table 1.

As we can see from Table 1, we divided the whole working range of braking force into twenty subareas with step of 0.01 (column - braking force range). For the purpose of modelling, as input we used the average of each range (column - applied value). The parameters of filters for 

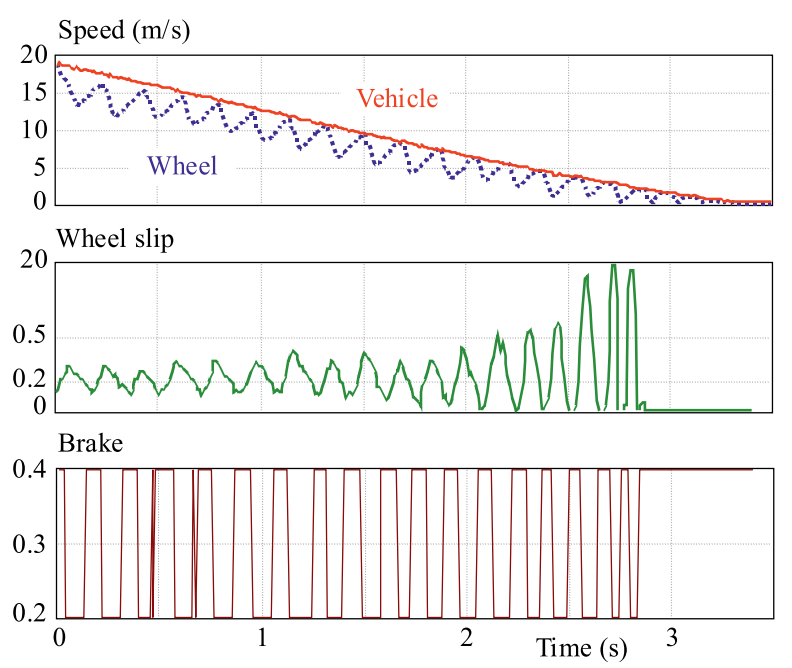

Fig. 2. Simple relay control

Table 2. Parameters of filter

\begin{tabular}{cccccc}
\hline $\begin{array}{r}\text { model } \\
\text { number }\end{array}$ & $p_{1}$ & $p_{2}$ & $c_{0}$ & $c_{1}$ & $c_{2}$ \\
\hline 1 & 42.754 & 21.877 & 0.000003 & 1.115 & -0.628 \\
2 & 72.736 & 19.377 & 0.000001 & 0.911 & -0.772 \\
3 & 16.009 & 15.121 & 0.000021 & 0.937 & -0.233 \\
4 & 35.177 & 5.123 & 0.000017 & 1.291 & -0.432 \\
5 & 13.106 & 5.907 & 0.000015 & 1.306 & -0.309 \\
6 & 3.957 & 48.573 & 0.000007 & 0.657 & -0.045 \\
7 & 30.519 & 8.112 & 0.0000025 & 1.463 & -1.076 \\
8 & 36.775 & 7.841 & 0.0000122 & 1.655 & -1.362 \\
9 & 31.806 & 5.593 & 0.000035 & 1.703 & -1.318 \\
10 & 64.021 & 4.191 & 0.000016 & 1.888 & -1.279 \\
11 & 62.121 & 4.397 & 0.000025 & 1.912 & -1.368 \\
12 & 20.716 & 6.395 & 0.000011 & 1.991 & -1.714 \\
13 & 22.491 & 6.350 & 0.000014 & 2.062 & -1.757 \\
14 & 23.775 & 6.442 & 0.000017 & 2.269 & -1.887 \\
15 & 31.761 & 5.891 & 0.000012 & 2.401 & -1.883 \\
16 & 39.231 & 5.051 & 0.000011 & 2.439 & -1.843 \\
17 & 47.706 & 4.406 & 0.000011 & 2.417 & -1.782 \\
18 & 48.742 & 4.507 & 0.000015 & 2.546 & -1.891 \\
19 & 48.058 & 4.064 & 0.000012 & 2.380 & -1.862 \\
20 & 14.005 & 4.738 & 0.000018 & 2.514 & -1.659 \\
\hline
\end{tabular}

Table 3. Comparative analysis of different control methods

\begin{tabular}{lcccc}
\hline Control method & $T_{z}$ & $E$ & $N$ & $J$ \\
\hline Relay control & 3.32 & 14.6764 & 44 & 4.9370 \\
\hline $\begin{array}{l}\text { SMC based on } \\
\text { orthogonal model }\end{array}$ & 0.95 & 8.3871 & 135 & 3.3181 \\
\hline
\end{tabular}

$\delta=1.002837$ are given in Table 2. Also, it can be noticed that parameter $c_{0}$ in Table 2 is very close to zero, so it can be neglected.

Now, for each linearized model we should design the appropriate sliding mode controller. The switching between controllers depends on the input signal (braking force) and it can be performed using program code or already developed tools in Matlab.
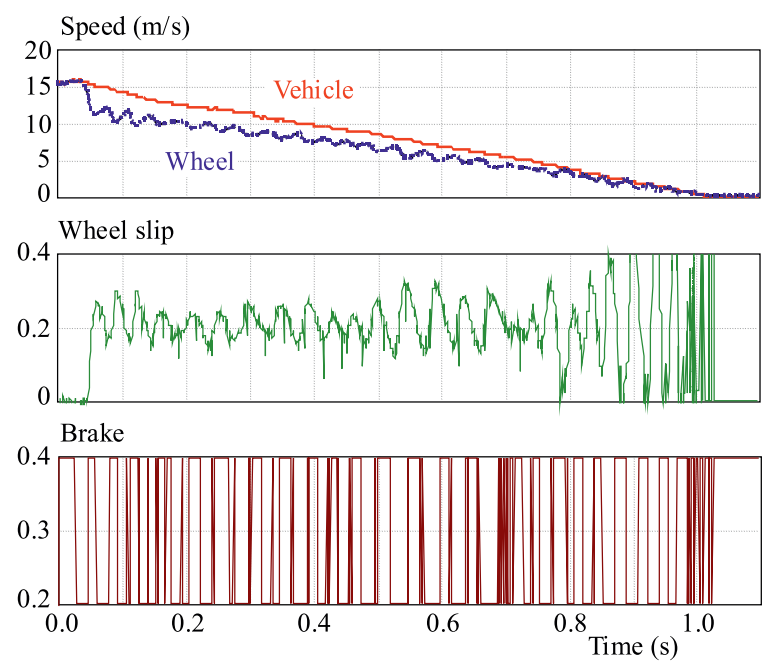

Fig. 3. Orthogonal sliding mode control

In order to design controller using the proposed method, the transfer function (18) must be converted into modified controllable canonical form (8). After applying procedure, described in Section 2, we obtain the following state space model of ABS

$$
\begin{gathered}
\dot{x}_{1}=d_{11} x_{1}+d_{12} x_{2}+k u, \\
\dot{x}_{2}=d_{21} x_{1}+d_{22} x_{2}, \\
y=x_{1}, \\
d_{11}=\frac{b_{0}-a_{1} b_{1}}{b_{1}}, \quad d_{12}=-b_{1}, k=b_{1}, \\
d_{21}=\frac{a_{0}+\left(b_{0} / b_{1}\right) d_{11}}{b_{1}}, \\
d_{22}=-\frac{b_{0}}{b_{1}} .
\end{gathered}
$$

For a given form of the system (19) and using (9), the sliding mode control can be designed in the following form

$$
u=-\frac{d_{11} x_{1}}{k}+\alpha \operatorname{sgn}\left(x_{1}^{\mathrm{ref}}-x_{1}\right)
$$

where $x_{1}$ represents the current slip value $\lambda$, with $\lambda_{\text {ref }}$ chosen to be 0.2 [25]. Parameter $\alpha$ is chosen in accordance with reaching and existence conditions of sliding mode.

\section{EXPERIMENTAL RESULTS}

For the purpose of comparison, we performed experiment with relay controller, given as a demo with the rest of manufacture (Inteco) software, and results are compared with those obtained by proposed sliding mode control using the almost orthogonal filter. The experimental results are shown in Figs. 2 and 3, respectively.

In Table 3, we use three parameters as relevant for evaluation of the quality of both controllers. The first parameter is $T_{z}$ and it represents stopping time, ie duration from the beginning of the braking process to a complete halt of the vehicle. The second parameter is the mean squared error, which is calculated by the formula $E=\int_{0}^{T_{z}}\left(\lambda-\lambda_{\text {ref }}\right)^{2} \mathrm{~d} t$. The third parameter is $N$ 


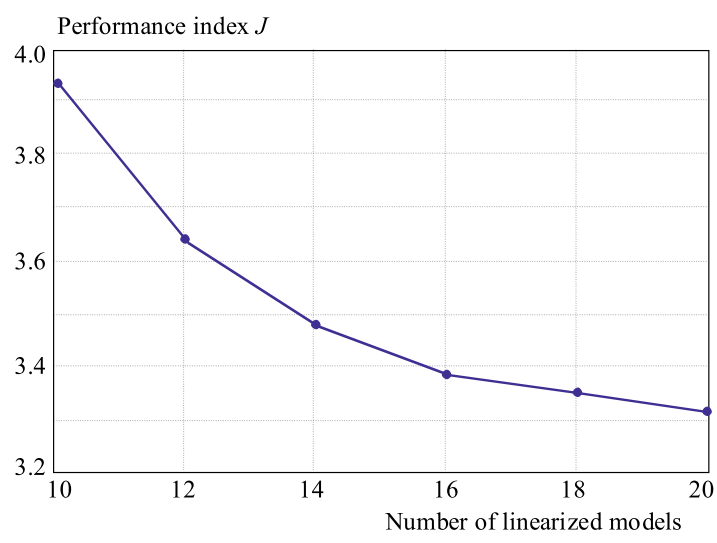

Fig. 4. Dependence of performance index and controller complexity

- the total number of changes in levels of control during the braking process reflecting wear of ABS system during working. It is obviously desirable for each of the control methods that all three parameters are as low as possible.

Using the orthogonal models with the sliding mode control improves performance of controlled system significantly. This can be best seen if we introduce a comprehensive performance index ( $J$ in Table 3 ), which combines all three, described above, relevant parameters for the analysis of the quality of designed controllers. This index is obtained by a simple formula: $J=2 k_{1} T_{z}+k_{2} E+k_{3} N$ where the coefficients $k_{1}, k_{2}$, and $k_{3}$ can be adjusted to emphasize the importance of each of the three relevant parameters on the overall performance index. The values in column $J$ of Table 3, were obtained by selecting $k_{1}=0.4684, k_{2}=0.0867$ and $k_{3}=0.0126$. These coefficients provide the normalization of the parameters with highlighting the importance of the stopping time of vehicles (the most important parameter for safety) by doubling the normalized values. The obtained values of the index confirm the quality of the performance of designed sliding mode control based on orthogonal models.

In the end, in Fig. 4 it is shown how the number of linearized models affects effectiveness of the proposed control method. As it can be seen, as the number of models increases the comprehensive performance index $J$ decreases, ie, the more sophisticated partitioning of working area implicates the better matching between linearized model and real system in the given area. However, we must always have in mind that better performance effects controller complexity and cost so our control algorithm should be employed only with more complicated processes when high controller complexity is justified and motivated, for example, by the human safety, like in our case.

\section{CONCLUSIONS}

In this paper we presented a new approach to the sliding mode control. Our control method is based on linearized models obtained using almost orthogonal filters of Müntz-Legendre type. These filters can be used for the modelling, identification, simulation, and analysis of different dynamical systems as well as for the designing of adaptive systems.

First, the mathematical background of sliding mode control based on modified controllable canonical form is given briefly. Then, in order to improve the existing sliding mode control, we used orthogonal models, obtained using orthogonal filters. In such a way, we can linearize any given system in its working areas with high percentage of accuracy, which is of great importance for controller design. After that, we developed sliding mode controller for each working area and the switching between control laws only depends on input signal.

In order to verify the proposed control approach, we applied it on an anti-lock braking system, characterized by strong nonlinear nature. The obtained results of the new design methodology have been compared with a classical relay controller and it has been shown that the proposed method has improved the system performances in terms of a smaller stopping time $i e$ the braking distance is significantly reduced, and lower tracking error. Finally, it is shown that higher number of models provides better control features, of course with the price of higher complexity and cost of designed controller.

\section{Acknowledgement}

This work was supported in part by the Serbian Ministry of Science and Technology within the projects III 43007, III 44006 and TR 35005.

\section{REFERENCES}

[1] UTKIN, V.-GULDNER, J.-SHI, J. : Sliding Mode Control in Electromechanical Systems, Taylor \& Francis, London, 1999.

[2] YOUNG, K. D.-UTKIN, V.-OZGUnER, U. : A Control Engineer's Guide to Sliding Mode Control, IEEE Transactions on Control Systems Technology 7 No. 3 (1999), 328-342.

[3] CAMACHO, O.-SMiTH, C.-MORENO, W.: Development of an Internal Model Sliding Mode Controller, Industrial \& Engineering Chemistry Research 42 No. 3 (2003), 568-573.

[4] KAPADIA, A. D.-WALKER, I. D.-DAWSON, D. M.-TATLICIOGLU, E. : A Model-Based Sliding Mode Controller for Extensible Continuum Robots, Proceedings of the 9th WSEAS International Conference on Signal Processing, Robotics and Automation, ISPRA'10, 2010, pp. 113-120.

[5] HerrmanN, G.-SPURGEON, S. K.-EDWARDS, C.: A Model-Based Sliding Mode Control Methodology Applied to the HDA-Plant, Journal of Process Control 13 No. 2 (2003), 129-138.

[6] QIAO, F.-ZHU, Q. M.-WINFIELD, A.-MELHUISH, C. : Design of Takagi-Sugeno Fuzzy Model based Sliding Mode Controllers for Nonlinear Systems, Proceedings of the 2nd Postgraduate Research Student Conference of CEMS, UWE, Bristol, UK, 2003.

[7] NARENDRA, K. S.-BALAKRISHNAN, J.-CILIZ, M. K.: Adaptation and Learning using Multiple Models, Switching, and Tuning, IEEE Control Systems 15 No. 3 (1995), 37-51.

[8] JOHANSEN, T. A.-FOSS, B. A.: Constructing NARMAX Models using ARMAX Models, International Journal of Control 58 No. 5 (1993), 1125-1153. 
[9] CHO, J.-PRINCIPE, J. C.-ERDOGMUS, D.-MOTTER, M. A. : Quasi-Sliding Mode Control Strategy based on Multiple-Linear Models, Neurocomputing 70 No. 4-6 (2007), 960-974.

[10] NIKOLIĆ, S.-ANTIĆ, D.-DANKOVIĆ, B.-MILOJKOVIĆ, M.-JOVANOVIĆ, Z.-PERIĆ, S. : Orthogonal Functions applied in Antenna Positioning, Advances in Electrical and Computer Engineering 10 No. 4 (2010), 35-42.

[11] ANTIĆ, D.-DANKOVIĆ, B.-NIKOLIĆ, S.-MILOJKOVIĆ, M.-JOVANOVIĆ, Z.: Approximation based on Orthogonal and Almost Orthogonal Functions, Journal of the Franklin Institute 349 No. 1 (2012), 323-336.

[12] MiLOJKOVIĆ, M.-NIKOLIĆ, S.-DANKOVIĆ, B.-ANTIĆ, D.-JOVANOVIĆ, Z. : Modelling of Dynamical Systems based on Almost Orthogonal Polynomials, Mathematical and Computer Modelling of Dynamical Systems 16 No. 2 (2010), 133-144.

[13] ISKRENOVIĆ, O.: Discrete Time Variable Structure Controller Synthesis for Third Order Objects with Finite Zero using Delta Transform, Journal of Electrical Engineering 55 No. 3-4 (2004), 71-76.

[14] ISKRENOVIĆ-MOMČILOVIĆ, O.: Discrete-Time Variable Structure Controller for Aircraft Elevator Control, Journal of Electrical Engineering 59 No. 2 (2008), 92-96.

[15] ISKRENOVIĆ-MOMČILOVIĆ, O.: Discrete-Time Variable Structure Controller Synthesis for Objects with Finite Zeros, Facta Universitatis, Series: Mechanics, Automatic Control and Robotics 2 No. 8 (1998), 757-772.

[16] EMELYANOV, S. V.-UTKIN, V. I.-TARAN, V. A.-KOSTYLEVA, N. E.-SHUBLADZE, A. M.-EZEROV, V. B.DYBROVSKY, E. N. : Variable Structure Control Systems Theory, Nauka, Moscow, 1970. (in Russian)

[17] UTKIN, V. I. : Sliding Modes in Optimization and Control, Springer-Verlag, New York, 1992.

[18] DRAŽENOVIĆ, B.: The Invariance Conditions in Variable Structure Systems, Automatica 5 No. 3 (1969), 287-295.

[19] DANKOVIĆ, B.-NIKOLIĆ, S.-MilOJKOVIĆ, M.-JOVANOVIĆ, Z. : A Class of Almost Orthogonal Filters, Journal of Circuits, Systems, and Computers 18 No. 5 (2009), 923-931.

[20] DANKOVIĆ, B.-ANTIĆ, D.-JOVANOVIĆ, Z.-NIKOLIĆ, S.-MILOJKOVIĆ, M. : Systems Modelling based on Legendre Polynomials, Proceedings of the 5th International Symposium on Applied Computational Intelligence and Informatics, SACI 2009, Timisoara, Romania, 28-29 May 2009, pp. 241-246.

[21] ANTIĆ, D.-NIKOLIĆ, S.-MILOJKOVIĆ, M.-DANKOVIĆ, N.-JOVANOVIĆ, Z.-PERIĆ, S. : Sensitivity Analysis of Imperfect Systems using Almost Orthogonal Filters, Acta Polytechnica Hungarica 8 No. 6 (2011), 79-94.

[22] Inteco, The Laboratory Anti-Lock Braking System Controlled from PC-User's Manual, 2008, Available at www.inteco.com.pl.

[23] PRECUP, R. E.-PREITL, S.-RĂDAC, B. M.-PETRIU, E. M.-DRAGOŞ, C. A.-TAR, J. K. : Experiment-Based Teaching in Advanced Control Engineering, IEEE Transactions on Education, 54 No. 3 (2011), 345-355.

[24] MILOJKOVIĆ, M. : Orthogonal Functions Applied in Modeling of Dynamical Systems and Control of Systems with Fuzzy Sliding Mode, PhD diss., Faculty of Electronic Engineering, Niš, 2012. (in Serbian)

[25] ZANTEN, A.-ERHARDT, R.-LUTZ, A. : Measurement and Simulation of Transients in Longitudinal and Lateral Tire Forces, SAE paper 900210 (1990), 300-318.

Received 11 October 2013

Staniša $\mathbf{L j}$. Perić received the BSc degree from the Faculty of Electronic Engineering, Niš, in 2009. He is currently working as a Teaching Assistant with the Department of Control Systems at the University of Niš, Faculty of Electronic Engineering. He is author and co-author more than 35 scientific papers of refereed journals and international/national conferences. His current research interests include sliding mode control, fuzzy control, control systems theory, genetic algorithms, and orthogonal systems.

Dragan S. Antić received the BSc degree from the Faculty of Electronic Engineering, Niš, in 1987, and his MSc degree from the University of Niš, in 1991. He received the $\mathrm{PhD}$ degree from the University of Niš, in 1994. He is currently working as a Full Professor with the Department of Control Systems at the University of Niš, Faculty of Electronic Engineering. He is author and co-author more than 180 scientific papers of refereed journals and international/national conferences. His research interests include sliding mode control, nonlinear systems, modelling and simulation of dynamic systems, bond graphs, and orthogonal systems.

Vlastimir D. Nikolić received the BSc degree from the Faculty of Mechanicai Engineering, Niš in 1978 and his MSc degree from the University of Belgrade in 1981. He received the $\mathrm{PhD}$ degree from the University of Belgrade, in 1984. He is currently working as a Full Professor with Department of Control Systems and Mechatronics of Faculty of Mechanical Engineering, Niš. He is author and co-author more than 150 scientific papers of refereed journals and international/national conferences. His research interests include optimal and stochastic control, modelling and simulation, intelligent control and robotics.

Darko B. Mitić received his BSc, MSc and PhD degrees in 1992, 1997 and 2006, respectively from the University of Niš Faculty of Electronic Engineering. He is currently working as an Assistant Professor with the Department of Control Systems at the University of Niš, Faculty of Electronic Engineering. He is author and co-author of more than 100 scientific papers that have appeared in conference proceedings and journals. His research interests include variable structure and nonlinear control systems, modelling and simulation of dynamic systems, model predictive control, orthogonal polynomials and signal processing.

Marko T. Milojković received the BSc degree from the Faculty of Electronic Engineering, Niš, in 2003, and MSc degree from the University of Niš, in 2008. He received the $\mathrm{PhD}$ degree from the University of Niš, in 2012. He is currently working as an Assistant Professor with the Department of Control Systems at the University of Niš, Faculty of Electronic Engineering. He is author and co-author more than 60 scientific papers of refereed journals and international/national conferences. His current research interests include the modelling and simulation of dynamic systems, sliding mode control, fuzzy control, and orthogonal systems.

Saša S. Nikolić received the BSc degree from the Faculty of Electronic Engineering, Niš, in 2006. He is currently working as a Teaching Assistant with the Department of Control Systems at the University of Niš, Faculty of Electronic Engineering. He is author and co-author more than 50 scientific papers of refereed journals and international/national conferences. His research interests include control systems theory, process control and identification, sliding mode control, and orthogonal systems. 